\title{
Bovine Spongiform Encephalopathy (BSE) - Infectious, Contagious, Zoonotic or Production Disease?
}

\author{
By Marcus G. Doherr
}

Department of Clinical Veterinary Medicine, University of Bern, Switzerland.

\begin{abstract}
Doherr MG: Bovine spongiform encephalopathy (BSE) - infectious, contagious, zoonotic or production disease? Acta vet. scand. 2003. Suppl. 98, 33-42. - In 1986, a new progressive neurological condition similar to scrapie of sheep and goats was recognised in cattle in the United Kingdom (UK), and was named bovine spongiform encephalopathy (BSE). There is an ongoing discussion whether BSE should be classified as infectious, contagious, or zoonotic, and if it fits the definition of a production disease. The objective of this work is to briefly describe the main characteristics of transmissible spongiform encephalopathies (TSE), to review the epidemiology of BSE, and to address the question of how to classify BSE. TSEs are characterised as chronic wasting diseases with spongiform vacuolation and the accumulation of infectious prion protein $\left(\mathrm{PrP}^{\mathrm{Sc}}\right)$ in the central nervous system. TSE infectivity is very difficult to inactivate. Cattle BSE most likely originated from sheep scrapie, although this will remain to be an issue for debate. The disease can be transmitted from cattle to a range of species, and has resulted in smaller TSE epidemics in domestic cats, zoo cats and zoo ruminants, and in humans. Transmission in the field occurred through feed containing ruminant-derived protein, and measures to prevent the recycling of infectivity have proven effective to reduce the number of new infections. Mandatory reporting of clinical suspects combined with targeted screening of risk populations is needed to assess the BSE status of a country. Infection studies and the transmissibility to other species classify BSE as infectious and zoonotic. Absence of excretion of the agent, and therefor of horizontal transmission, categorise BSE as non-contagious. However, BSE is a multifactorial infectious disease that is dependent on management factors (mainly feeding), and therefore fits into the broader definition of production diseases.
\end{abstract}

Spongiform encephalopathy; epidemiology; production disease; cattle; surveillance.

\section{Introduction}

In 1986, a new clinical disease in cattle was recognised in the United Kingdom (UK). It was classified as a progressive neurological condition similar to scrapie of sheep and goats, and was named bovine spongiform encephalopathy (BSE) (Wells et al. 1987). Other transmissible spongiform encephalopathies (TSE) had been described before the occurrence of BSE, namely scrapie of sheep and goats (first ob- served/described as a clinical entity around 1730), a transmissible mink encephalopathy (TME, 1947), a chronic wasting disease of North American deer and elk (CWD, 1978), and the human TSEs sporadic CreutzfeldtJakob disease (sCJD, 1920), Gerstmann-Sträussler-Scheinker Syndrom (GSS, 1928), Kuru (1957), and fatal familiar insomnia (FFI, 1986). These TSEs can arise spontaneously (sCJD), be 
inherited (FFI, GSS), or are naturally or accidentally transmitted (scrapie, Kuru, CWD, BSE). Some of them possess several of these properties (Hartsough \& Burger 1965, Detwiler 1992, Kimberlin 1992, Williams \& Young 1992, Will 1993, Hoinville 1996, Spraker et al. 1997, Prusiner 1998a). There is an ongoing discussion whether BSE should be classified as infectious, contagious, or zoonotic, and if it fits the definition of a production disease. The objective of this work is to briefly describe the main characteristics of TSEs, to review the epidemiology of BSE, and to address the question of how to classify BSE.

\section{Characteristics of prion diseases}

All known TSEs are characterised by an accumulation of prions ("proteinacious infectious particles", PrP) and vacuolation of the CNS in the final stages of the disease. $\operatorname{PrP}^{\mathrm{C}}$ is routinely synthesised by various cells, and is metabolised (digested) by proteinase K (enzymes). The infectious prion protein, denoted $\mathrm{PrP}^{\mathrm{Sc}}$ or $\mathrm{PrP}^{\mathrm{res}}$, is partly proteinase $\mathrm{K}$ resistant. It forms oligomers, accumulates mainly in the cells of the CNS, and results in the specific histopathological changes observed in the differed TSEs (Prusiner 1998b). Both $\mathrm{PrP}^{\mathrm{C}}$ and $\mathrm{PrP}^{\mathrm{Sc}}$ have the same aminoacid sequence, but they have different three-dimensional structures: $\operatorname{PrP}^{\mathrm{C}}$ in $42 \%$ is composed of structures called alpha helices, and has only a few beta sheets (Lopez Garcia et al. 2000). The infectious $\mathrm{PrP}^{\mathrm{Sc}}$ has only $30 \%$ alpha helices, and more than $40 \%$ beta sheets. The transition of $\operatorname{PrP}^{\mathrm{C}}$ to $\mathrm{PrP}^{\mathrm{Sc}}$, based on the prion dimer theory of Prusiner, occurs by merging of a normal (healthy) and an infectious prion molecule to form a $\mathrm{PrP}^{\mathrm{C}}-\mathrm{PrP}^{\mathrm{Sc}}$ heterodimer, in which the normal $\operatorname{PrP}^{\mathrm{C}}$ molecule is restructured into $\mathrm{PrP}^{\mathrm{Sc}}$. After separation of the 2 molecules, 2 new $\mathrm{PrP}^{\mathrm{Sc}}$ homodimers have been created which again can convert healthy $\mathrm{PrP}^{\mathrm{C}}$ molecules (Prusiner 1998b). It still is de- bated whether $\mathrm{PrP}^{\mathrm{Sc}}$ and TSE infectivity are one and the same, or if there is an additional factor "X" (protein, virion, virus?) besides exposure to $\mathrm{PrPSC}$ required to result in a TSE infection (Telling et al. 1995).

TSE infectivity is difficult to destroy (decontaminate). The most efficient method is application of wet heat (autoclaving) after treatment with sodium hydroxide (1-2M NaOH). Application of dry heat will conserve TSE infectivity, and temperatures up to $600{ }^{\circ} \mathrm{C}$ have been described as insufficient to fully eliminate it from brain tissue cubes (Brown et al. 1990, 2000). The commonly used methods to treat MBM during rendering $\left(133^{\circ} \mathrm{C}\right.$ at 3 bars for $20 \mathrm{~min}$ utes) will reduce TSE infectivity by at least $98 \%$, but not always by $100 \%$ (Taylor et al. 1998, 1999, Schreuder et al. 1998, Taylor 1999, 2000). TSE infectivity, once excreted, can survive in the environment (soil) for several years, as has been demonstrated with the scrapie agent (Brown \& Gajdusek 1991).

\section{Epidemiology of BSE}

The origin of BSE (as a cattle disease) is an issue of controversial debate, but it is unlikely that this controversy will ever be resolved. The most widely accepted hypothesis is that cattle BSE originated from sheep scrapie, i.e. that one of the British sheep scrapie strains was recycled with MBM to cattle, and was (or became during recycling) infectious for cattle. After this adaptation, on-going intra-species recycling caused the BSE epidemic in British cattle (Schreuder 1993, Taylor 1995). Alternatively, a spontaneous mutation in the genome coding for the PrP gene, similar to sporadic CJD in humans, could have resulted in a TSE strain either in sheep or in cattle that was subsequently infectious for - and recycled to - cattle. The introduction of BSE from a wildlife population seems to be a less realistic hypothesis. Large scale recycling of BSE infectivity in the UK be- 


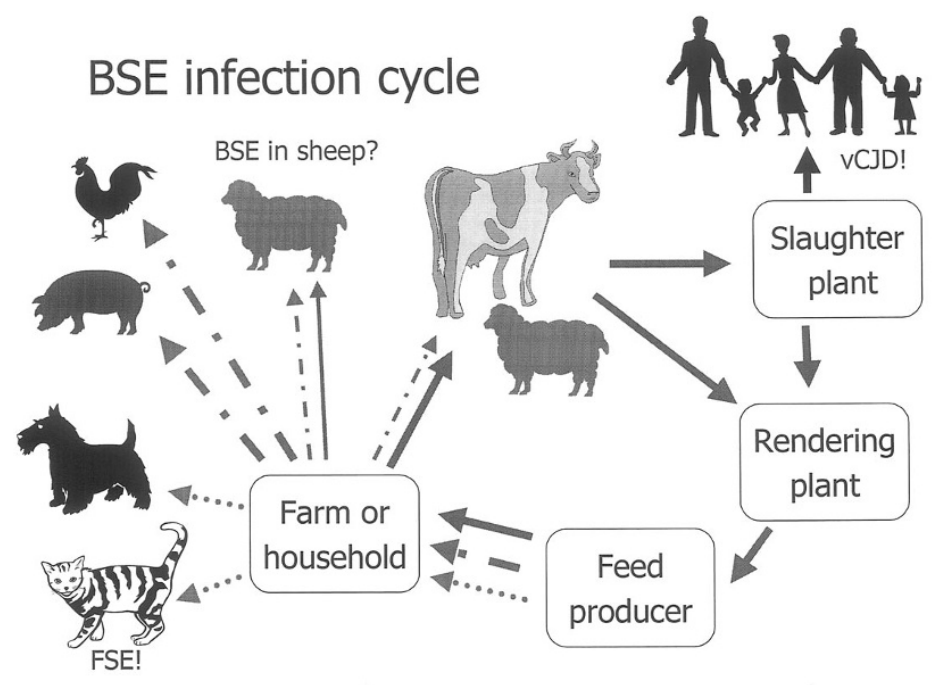

Figure 1. BSE infection cycle and exposure of other species to products of cattle origin. Solid arrows (-)indicate direct exposure to cattle-derived products (cattle-derived food, cattle feed), broken arrows (---) indicate exposure to feed produced for pigs or poultry, and dotted arrows (…) indicate an exposure to feed produced for pets (dogs and cats).

came possible after 1970 when changes in the tallow (fat) extraction during MBM rendering from solvent-based (wet, higher temperatures) to pressure-based (dry, lower temperatures) allowed the infectious agent to survive (Wilesmith et al. 1991, Kimberlin 1992).

Epidemiological studies on the clinical BSE cases diagnosed in UK in 1986 and 1987 highlighted the increased risk for BSE on farms that had fed cattle concentrates containing meat and bone meal (MBM). The recycling of ruminantderived MBM to ruminants and other farm animals via concentrate feed was common practice in the UK and other countries (Fig. 1) (Wilesmith et al. 1988, 1992a, 1992b, Hoinville et al. 1995, Anderson et al. 1996). Cattle concentrates contained up to $6 \%$ protein of either animal or plant origin. As a consequence of the studies linking MBM use to BSE, this inclusion of MBM into ruminant feed was banned in the UK in July 1988, and in Switzerland in Decem- ber 1990. These bans resulted in a significant reduction of new infections in cattle born after their implementation, thereby highlighting the importance of controlling this exposure route (Fig. 2). The secondary increase in BSE cases by birth cohort seen in Switzerland might be the result of an increase in the number of infected cattle reaching clinical levels of disease, and increase of MBM imports from neighbouring European countries, and increase in the surveillance activities since 1999, or a combination of those factors.

BSE cases born after these MBM bans (denoted BAB cases) documented the presence of other infection routes besides routine inclusion of MBM in cattle concentrates. Cross-contamination of cattle feed with feed for pigs and poultry during production, transportation or storage, and cross-exposure of cattle to pig or poultry feed on mixed-species farms were suggested as additional infection routes (Fig. 1) 


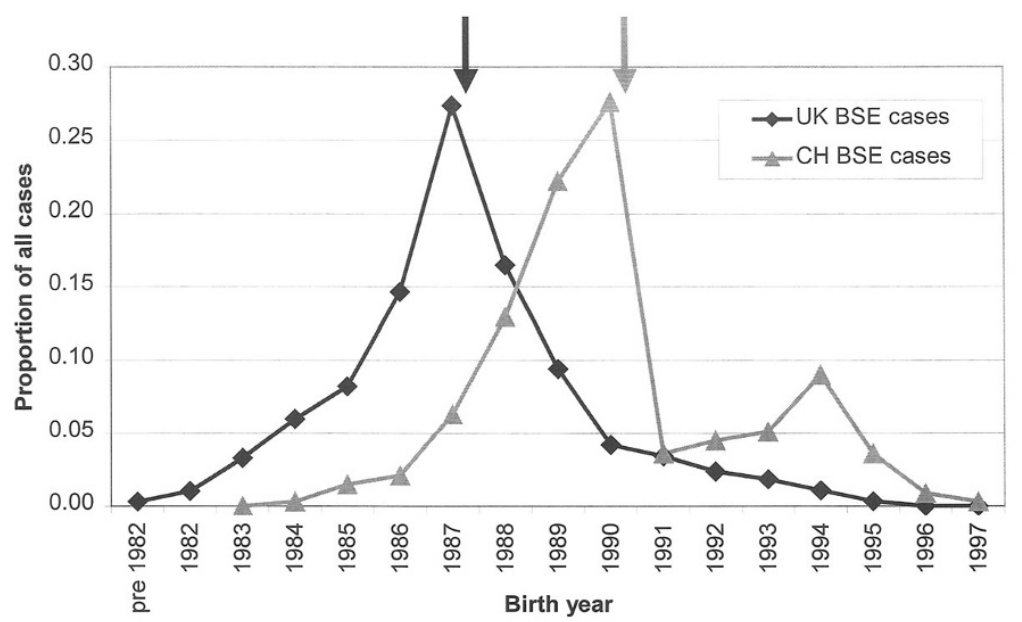

Figure 2. Proportion of all British (- -) and Swiss (- - -) BSE cases with known birth date (y axis) by birth year (x axis). The immediate drop in cases in the year after the first ban of feeding meat and bone meal to cattle (UK July 1988, CH Dec 1990, as indicated by the arrows) highlight the strong (causal) association between MBM feeding and BSE (data as of August 2001).

(Hoinville 1994, Hoinville et al. 1995). The Scientific Steering Committee (SSC) of the European Commission in a geographic BSE risk assessment exercise (GBR) listed several risk factors for BSE propagation (spread within a cattle population) including the structure and intensity of the cattle population and other livestock populations, production and use of ruminant-derived meat-and-bone meal (including feed bans), the use of specified risk material (SRM) and carcasses (including SRM bans) and the rendering industry (structure, technology, rendering parameters) (Alban et al. 2000, SSC 2000a). The most important measures to prevent exposure of cattle to BSE are the ban of feeding ruminant protein back to cattle ("MBM ban"), the exclusion of all high risk material such as brain and spinal cord of cattle and cattle carcasses from MBM production ("SRM ban"), the treatment of produced MBM at $133^{\circ} \mathrm{C}$ and 3 bars for $20 \mathrm{~min}$ (EU standard), and the prevention of cross contamination during feed production and use. Blocking of the known and suspected feed-related routes of BSE transmission has resulted in a documented decline in the number of new infections in subsequent birth cohorts in the UK, in Switzerland (Fig. 2), and in other countries. Due to the long incubation time of BSE, however, it takes several years until the effectiveness of implemented measures to prevent new BSE infections can be reliably assessed.

\section{Pathogenesis}

Experimental oral inoculation of calves and sequential slaughter done in the UK documented that BSE infectivity was only present in the anatomical region of the Peyers patches of the distal ileum at distinct time points during the incubation period, and in the central nervous system (CNS: brain, spinal cord, dorsal root ganglia) late in incubation (few months before clinical disease) and during clinical disease. In cattle, BSE infectivity has not been docu- 
Table 1. Implementation of mandatory reporting for bovine spongiform encephalopathy (BSE), year of the first BSE cases, implementation of a targeted screening, total BSE case numbers in 2000 and 2001, and assessment of the overall BSE surveillance system in the European Union Member States and Switzerland as of December $21,2001$.

\begin{tabular}{|c|c|c|c|c|c|c|c|c|}
\hline \multirow{2}{*}{ Country } & \multirow{2}{*}{$\begin{array}{l}\text { Adult } \\
\text { cattle } \\
\text { pop. }{ }^{1}\end{array}$} & \multirow{2}{*}{$\begin{array}{l}\text { Mandatory } \\
\text { reporting } \\
\text { since } \\
\text { (year) }\end{array}$} & \multicolumn{2}{|c|}{$\begin{array}{c}\text { First reported BSE } \\
\text { case (OIE) }\end{array}$} & \multicolumn{3}{|c|}{$\begin{array}{c}\text { Detected BSE cases } \\
\text { (OIE) }\end{array}$} & \multirow{2}{*}{$\begin{array}{l}\text { Surveillance system } \\
\text { meets OIE requirements } \\
\text { (GBR June 2000) }\end{array}$} \\
\hline & & & $\begin{array}{l}\text { Imported } \\
\text { cattle }\end{array}$ & $\begin{array}{l}\text { Domestic } \\
\text { cattle }\end{array}$ & 2000 & $2001^{3}$ & Total & \\
\hline Austria & 1.0 & 1991 & - & - & 0 & 1 & 1 & No \\
\hline Belgium & 1.5 & 1990 & - & 1997 & 9 & 46 & 65 & Yes \\
\hline Denmark & 0.9 & 1990 & 1992 & 2000 & 1 & 6 & 7 & No \\
\hline Finland & 0.4 & 1990 & - & - & 0 & 1 & 1 & Yes \\
\hline France & 11.0 & 1990 & 2000 & 1991 & 162 & 258 & 499 & No \\
\hline Germany & 6.6 & 1990 & 1992 & 2000 & 7 & 125 & 132 & Yes \\
\hline Greece & 0.3 & $?$ & - & 2001 & 0 & 1 & 1 & No data available \\
\hline Ireland & 3.4 & 1989 & 1989 & 1989 & 149 & 220 & 799 & No \\
\hline Italy & 3.4 & 1991 & 1994 & 2001 & 0 & 48 & 48 & Yes \\
\hline Luxembourg & 0.1 & 1990 & - & 1998 & 0 & 0 & 1 & No \\
\hline Netherlands & 1.8 & 1990 & - & 1997 & 2 & 20 & 28 & Yes \\
\hline Portugal & 0.8 & 1990 & 1990 & 1994 & 163 & 67 & 591 & Yes \\
\hline Spain & 3.4 & 1990 & - & 2000 & 2 & 82 & 84 & No \\
\hline Sweden & 0.7 & 1989 & - & - & 0 & 0 & 0 & Yes \\
\hline $\mathrm{UK}^{2}$ & 5.3 & 1988 & - & 1986 & 1443 & $\sim 800$ & 181642 & Yes \\
\hline Switzerland & 0.9 & 1990 & - & 1990 & 33 & 42 & 408 & Yes \\
\hline
\end{tabular}

Sources: OIE (www.oie.int), various European Commission internet sites, the GBR opinions and the GBR country reports.

${ }^{1}$ Million cattle above 24 months of age (Source: Eurostat).

${ }^{2}$ United Kingdom: data from 1987 include year 1986; data for 2001 are incomplete.

${ }^{3}$ Data for 2001 might be incomplete due to delayed reporting to the OIE.

mented in meat, milk, blood, urine, lymph nodes or any other tissue besides the CNS and the distal ileum wall (Middleton \& Barlow 1993, Taylor et al. 1995, Wells et al. 1994, 1998). One report in which sternal bone marrow isolated from a clinical BSE case in one of the experimentally exposed mice induced a TSE was never reproduced, and was later speculated to have been cross-contamination. Without excretion of the infectious agent during incubation or clinical disease, direct horizontal transmission (from infected to susceptible cattle) does not occur. BSE infectivity levels of CNS tissue from clinically diseased cattle have been titrated in cattle, and there is evidence that 0.1 gram of brain tissue is sufficient to orally in- fect calves with BSE. Direct intracerebral inoculation of the infectious agent into susceptible mice strains seems to be 500 to 1000 times more efficient than oral exposure of the mice, and this method is used extensively to study the distribution of BSE infectivity in various tissues of experimentally infected animals or field cases, and to differentiate between BSE and other TSE strains.

\section{BSE spread and surveillance}

Introduction of the BSE agent into recipient countries has occurred by live animal trade, and by direct or indirect trade between BSE-effected and BSE-free countries with MBM and other products potentially containing BSE in- 


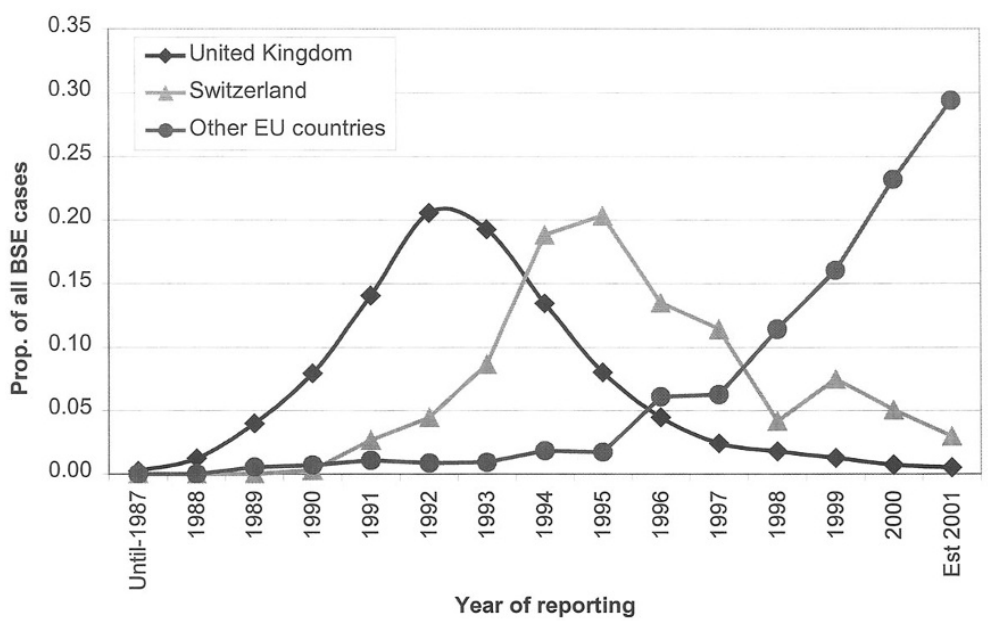

Figure 3. Proportion of all British (- - ), Swiss $\left(-\boldsymbol{\Delta}_{-}\right)$and other European countries combined (- - ) clinical BSE cases (y axis) by year of reporting (x axis). The figures for 2001 were extrapolated from the case numbers observed until November 24, 2001.

fectivity (Hörnlimann et al. 1994, Nathanson et al. 1997, Schreuder et al. 1997). The GBR done by the EU indicated a rather wide geographic distribution of the disease, and this has been confirmed by the surveillance activities implemented since the year 2000. Domestic BSE cases by now have been detected in all but one of the EU Member States (Sweden) as well as in Switzerland (Table 1). In addition, in 2001 Slovakia (4 cases), Japan (3), the Czech Republic (2) and Slovenia (1) experienced their first domestic BSE cases. Based on the GBR, additional countries such as Albania, Estonia, Hungary, Lithuania, Poland and Cyprus are expected to harbour BSE-infected cattle (SSC 2000a, 2001).

BSE case detection until 1998 was restricted to the mandatory reporting and subsequent investigation of clinical suspect cases ("passive" surveillance). Since 1999 EU-validated fast screening assays such as the Prionics check Western blot or the BioRad Platelia ELISA have become available as a surveillance tool for targeted "high-risk" cohorts ("active" surveillance). This type of combined passive and active BSE surveillance was implemented in Switzerland in January of 1999, and is mandatory for the EU member states since January 1, 2001 (Doherr et al. 1999, 2001, 2002, Schaller et al. 1999, SSC 2000b, Schiermeier 2001). Data from the Swiss surveillance indicated that mandatory suspect reporting captured less than $50 \%$ of the detectable BSE cases that were removed from the population (Doherr et al. 1999, 2001). In other countries passive surveillance might have completely missed a low number of clinical BSE cases for some periods of time. In recent years, however, an increase also in the number of clinical BSE cases was seen in continental Europe (Fig. 3) in addition to the cases detected by the passive surveillance. The combination of passive and active surveillance components therefore seem essential to reliably assess the BSE status of a given country or region. However, the EU-validated screening assays rely on the post mortem detection of $\mathrm{PrP}^{\mathrm{Sc}}$ 
in brain tissue (homogenate), and are validated only for cattle with clinical BSE (Moynagh \& Schimmel 1999, Schaller et al. 1999, Oesch et al. 2000, Deslys et al. 2001). No BSE test is available for detection of animals during early incubation, and we have to assume that a considerable number of such cattle leaves the population undetected. Some ante mortem tests have been announced in the media, however, none has been commercialised so far.

\section{Transmission of BSE to other species}

Transmission of BSE to other species is possible. This has been documented in experimental infection of several species, but also in the observed FSE epidemic in domestic cats (over 90 cases in the UK reported since 1990), in ruminants and large cats kept in British zoos, and by the epidemic of the new variant of CreutzfeldtJakob disease (vCJD) in humans with over 100 cases in the UK and 4 cases reported from France so far (Pearson et al. 1991, Wyatt et al. 1991, Wells \& McGill 1992, Schreuder 1994, Collinge et al. 1996, Will et al. 1996, Hill et al. 1997).

BSE can be orally transmitted to sheep and goats where it results in a TSE very similar to scrapie (Foster et al. 1993, 1996). No field cases of BSE in sheep have yet been diagnosed, however, differentiation to sheep scrapie is only possible by strain typing in mice bioassays, which takes several years to perform. Attempts to orally infect pigs or poultry with BSE failed so far (Dawson et al. 1990, Done 1990, Meldrum 1990).

\section{Conclusions}

BSE is a new disease in cattle. Infectivity can be titrated, and the disease has been transmitted to the same and to other species including cats and humans. This classifies BSE as infectious and zoonotic. However, even cattle in the final stages of (clinical) disease do not actively ex- crete the infectious agent, and horizontal transmission comparable with that of foot-andmouth disease (FMD), classical swine fever (CSF) or even sheep scrapie does not occur; the disease therefore is not considered to be contagious. The term "production diseases" traditionally was used exclusively for metabolic diseases that were induced by management practices. More recently, the definition of production diseases has been widened to include other traits such as infertility, and multifactorial diseases such as mastitis and lameness that might involve infectious agents but that are exacerbated by nutritional or management factors (Nir Markusfeld 2001). BSE, which is caused by an infectious agent (even though some "infectiologists" might not agree to classify prion diseases as such) and is dependent on management factors, would fit into the broader definition of production diseases. This, however, could be true for the majority of diseases that currently affect our animal production systems.

\section{References}

Alban L, de Koeijer AA, Heim D, Hueston WD, Kreysa J, Roberts MG: Assessment of the geographical risk of bovine spongiform encephalopathy - a proposal. Proceedings of the 9th Conference of the International Society for Veterinary Epidemiology and Economics, August 611, 2000, Breckenridge, Colorado (USA).

Anderson RM, Donnelly CA, Ferguson NM, Woolhouse ME, Watt CJ, Udy HJ, MaWhinney S, Dunstan SP, Southwood TR, Wilesmith JW, Ryan JB, Hoinville LJ, Hillerton JE, Austin AR, Wells GAH: Transmission dynamics and epidemiology of BSE in British cattle. Nature 1996, 382: 779788.

Brown P, Liberski PP, Wolff A, Gajdusek DC: Resistance of scrapie infectivity to steam autoclaving after formaldehyde fixation and limited survival after ashing at 360 degrees C: practical and theoretical implications. J. Infect. Dis. 1990, 161(3): 467-472.

Brown P \& Gajdusek DC: Survival of scrapie virus after 3 years' interment. Lancet 1991, 337(8736): 269-270. 
Brown P, Rau EH, Johnson BK, Bacote AE, Gibbs CJJ, Gajdusek DC: New studies on the heat resistance of hamster-adapted scrapie agent: threshold survival after ashing at 600 degrees $\mathrm{C}$ suggests an inorganic template of replication. Proc. Natl. Acad. Sci. U.S.A. 2000, 97(7): 34183421.

Collinge J, Sidle KC, Meads J, Ironside J, Hill AF: Molecular analysis of prion strain variation and the aetiology of 'new variant' CJD. Nature 1996, 383(6602): 685-690.

Dawson M, Wells GAH, Parker BNJ, Scott AC: Primary parenteral transmission of bovine spongiform encephalopathy to the pig. Vet. Rec. 1990, 127: 338.

Deslys JP, Comoy E, Hawkins S, Simon S, Schimmel $H$, Wells G, Grassi J, Moynagh J: Screening slaughtered cattle for BSE. Nature 2001, 409 (6819): 476-478.

Detwiler LA: Scrapie. Rev. Sci. Tech. Off. Int. Epiz. 1992, 11(2): 491-537.

Doherr MG, Oesch B, Moser M, Vandevelde M, Heim $D$ : Targeted surveillance for bovine spongiform encephalopathy. Vet. Rec. 1999, 145: 672.

Doherr MG, Heim D, Fatzer R, Cohen CH, Vandevelde $M$, Zurbriggen A: Targeted screening of high-risk cattle populations for BSE to augment mandatory reporting of clinical suspects. Prev. Vet. Med. 2001, 51(1-2): 3-16.

Doherr MG, Hett AR, Cohen CH, Fatzer R, Rüfenacht J, Zurbriggen A, Heim D: Trends in prevalence of BSE in Switzerland based on fallen stock and slaughter surveillance. Vet. Rec. 2002, 150: 347-348.

Done JT: Spongiform encephalopathy in pigs. Vet. Rec. 1990, 127(19): 484.

Foster JD, Hope J, Fraser H: Transmission of bovine spongiform encephalopathy to sheep and goats. Vet. Rec. 1993, 133(14): 339-341.

Foster JD, Bruce M, Mc Connell I, Chree A, Fraser H: Detection of BSE infectivity in brain and spleen of experimentally infected sheep. Vet. Rec. 1996, 138(22): 546-548.

Hartsough GR \& Burger D: Encephalopathy of mink. I. Epizootiologic and clinical observations. J. Inf. Dis. 1965, 115: 387-392

Hill AF, Desbruslais M, Joiner S, Sidle KC, Gowland $I$, Collinge J, Doey LJ, Lantos P: The same prion strain causes vCJD and BSE. Nature 1997, 389(6650): 448-450.

Hoinville LJ: Decline in the incidence of BSE in cattle born after the introduction of the 'feed ban'.
Vet. Rec. 1994, 134: 274-275.

Hoinville LJ, Wilesmith JW, Richards MS: An investigation of risk factors for cases of bovine spongiform encephalopathy born after the introduction of the 'feed ban'. Vet. Rec. 1995, 136(13): 312318.

Hoinville LJ: A review of the epidemiology of scrapie in sheep. Rev. Sci. Tech. Off. Int. Epiz. 1996, 15(3): 827-852.

Hörnlimann B, Guidon D, Griot C: Risikoeinschätzung für die Einschleppung von BSE [Risk assessment for importing bovine spongiform encephalopathy]. Deutsche Tierärztliche Wochenschrift 1994, 101(7): 295-298.

Kimberlin RH: Bovine spongiform encephalopathy. Rev. Sci. Tech. Off. Int. Epiz. 1992, 11(2): 347390.

Lopez Garcia F, Zahn R, Riek R, Wuthrich K: NMR structure of the bovine prion protein. Proc. Natl. Acad. Sci. U.S.A. 2000, 97(15): 8334-8339.

Meldrum KC: Transmission of BSE to a pig. Vet. Rec. 1990, 127: 362.

Middleton DJ \& Barlow RM: Failure to transmit bovine spongiform encephalopathy to mice by feeding them with extraneural tissues of affected cattle. Vet. Rec. 1993 132: 545-547.

Moynagh J \& Schimmel H: Tests for BSE evaluated. Nature 1999, 400(6740): 105.

Nathanson N, Wilesmith JW, Griot C: Bovine spongiform encephalopathy (BSE): causes and consequences of a common source epidemic. Am. J. Epidemiol. 1997, 145(11): 959-969.

Nir Markusfeld $O$ : What are production diseases, and how do we manage them? 11th International Conference on Production Diseases in Farm Animals, 12-16 August 2001, Frederiksberg, Denmark. Acta vet scand. 2003, Suppl. 98, ???

Oesch B, Doherr MG, Heim D, Fischer K, Egli S, Bolliger $S$, Biffiger $K$, Schaller $O$, Vandevelde $M$, Moser M: Application of Prionics Western blotting procedure to screen for BSE in cattle regularly slaughtered at Swiss abattoirs. Archives Virol. [Suppl.] 2000, 16: S189-S195.

Pearson GR, Gruffydd_Jones TJ, Wyatt JM, Hope J, Chong A, Scott AC, Dawson M, Wells GA: Feline spongiform encephalopathy. Vet. Rec. 1991, 128(22): 532.

Prusiner $S B$ : The prion diseases. Brain Pathology 1998a, 8(3): 499-513.

Prusiner SB: Prions. Proc. Natl. Acad. Sci. U.S.A. 1998b, 95(23): 13363-13383.

Schaller O; Fatzer R; Stack M; Clark J; Cooley W; 
Biffiger $K$; Egli $S$; Doherr $M$; Vandevelde $M$; Heim D; Oesch B, Moser M: Validation of a Western immunoblotting procedure for bovine $\mathrm{PrP}^{\mathrm{SC}}$ detection and its use as a rapid surveillance method for the diagnosis of bovine spongiform encephalopathy (BSE). Acta Neuropathol. 1999, 98(5): 437-443.

Schiermeier Q: Testing times for BSE. Nature 2001, 409: 658-659.

Schreuder BEC: General aspects of transmissible spongiform encephalopathies and hypotheses about the agents. Vet. Q. 1993, 15(4): 167-174.

Schreuder BEC: Animal spongiform encephalopathies - an update. Part 1. Scrapie and lesser known animal spongiform encephalopathies. Vet. Q. 1994, 16(3): 174-181.

Schreuder BEC, Wilesmith JW, Ryan JBM, Straub $O C$ : Risk of BSE from the import of cattle from the United Kingdom into countries of the European Union. Vet. Rec. 1997, 141(8): 187-190.

Schreuder BEC, Geertsma RE, van Keulen LJ, van Asten JA, Enthoven P, Oberthur RC, de Koeijer $A A$, Osterhaus $A D$ : Studies on the efficacy of hyperbaric rendering procedures in inactivating bovine spongiform encephalopathy (BSE) and scrapie agents. Vet. Rec. 1998, 142(18): 474-480.

SSC, 2000a: Final Opinion of the Scientific Steering Committee on the Geographical Risk of Bovine Spongiform Encephalopathy (GBR). Opinion of the Scientific Steering Committee of the European Commission (adopted 6. July 2000)

SSC, 2000b: Commission Decision 2000/374/EC of 5 June 2000 amending Decision 98/272/EC on epidemio-surveillance for transmissible spongiform encephalopathies. Official Journal of the European Communities 135: 27-35.

Spraker TR, Miller MW, Williams ES, Getzy DM, Adrian WJ, Schoonveld GG, Spowart $R A$, O'Rourke KI, Miller JM, Merz PA: Spongiform encephalopathy in free-ranging mule deer (Odocoileus hemionus), white-tailed deer (Odocoileus virginianus) and Rocky Mountain elk (Cervus elaphus nelsoni) in northcentral Colorado. J. Wildl. Dis. 1997, 33(1): 1-6.

Taylor DM, Ferguson CE, Bostock CJ, Dawson M: Absence of disease in mice receiving milk from cows with bovine spongiform encephalopathy. Vet. Rec. 1995, 136(23): 592.

Taylor DM, Fernie K, McConnell I, Ferguson CE, Steele PJ: Solvent extraction as an adjunct to rendering: the effect on BSE and scrapie agents of hot solvents followed by dry heat and steam. Vet.
Rec. 1998, 143(1): 6-9.

Taylor DM: Inactivation of prions by physical and chemical means. J. Hosp. Infect. 1999, 43 Suppl: S69-S76.

Taylor DM, Fernie K, McConnell I, Steele PJ: Survival of scrapie agent after exposure to sodium dodecyl sulphate and heat. Vet. Microbiol. 1999, 67(1): 13-16.

Taylor DM: Inactivation of transmissible degenerative encephalopathy agents: A review. Vet. J. 2000, 159(1): 10-17.

Taylor K: Origin of BSE. Vet. Rec 1995, 137(26): 674-675.

Telling GC, Scott M, Mastrianni J, Gabizon R, Torchia M, Cohen FE, DeArmond SJ, Prusiner $S B$ : Prion propagation in mice expressing human and chimeric PrP transgenes implicates the intraction of cellular PrP with another protein. Cell 1995, 83: 79-90.

Wells GA, Scott AC, Johnson CT, Gunning RF, Hancock RD, Jeffrey $M$, Dawson M, Bradley R: A novel progressive spongiform encephalopathy in cattle. Vet. Rec. 1987, 121 (18): 419-420.

Wells GA \& McGill IS: Recently described scrapielike encephalopathies of animals: case definitions. Res. Vet. Sci. 1992, 53(1): 1-10.

Wells GAH, Dawson M, Hawkins SAC, Green RB, Dexter I, Francis ME, Simmons MM, Austin AR, Horigan $M W$ : Infectivity in the ileum of cattle challenged orally with bovine spongiform encephalopathy. Vet. Rec. 1994, 135: 40-41.

Wells GAH, Hawkins SAC, Green RB, Austin AR, Dexter I, Spencer YI, Chaplin MJ, Stack MJ, Dawson M: Preliminary observations on the pathogenesis of experimental bovine spongiform encephalopathy (BSE): an update. Vet. Rec. 1998, 142: 103-106.

Wilesmith JW, Wells GAH, Cranwell MP, Ryan JBM: Bovine spongiform encephalopathy: epidemiological studies. Vet. Rec. 1988, 123(25): 638644.

Wilesmith JW, Ryan JBM, Atkinson MJ: Bovine spongiform encephalopathy: epidemiological studies on the origin. Vet. Rec. 1991, 128: 199203.

Wilesmith JW, Ryan JB, Hueston WD, Hoinville LJ: Bovine spongiform encephalopathy: epidemiological features 1985 to 1990 . Vet. Rec. 1992a, 130(5): 90-94.

Wilesmith JW, Ryan JBM, Hueston WD: Bovine spongiform encephalopathy: case-control studies of calf feeding practices and meat and bonemeal 
inclusion in proprietary concentrates. Res. Vet. Sci. 1992b, 52: 325-331.

Will RG: Epidemiology of Creutzfeldt-Jakob disease. Br. Med. Bull. 1993, 49(4): 960-970.

Will RG, Ironside JW, Zeidler M, Cousens SN, Estibeiro K, Alperovitch A, Poser S, Pocchiari M, Hofman A, Smith $P G$ : A new variant of Creutzfeldt-Jakob disease in the UK. Lancet 1996, 347(9006): 921-5.
Williams ES \& Young S: Spongiform encephalopathies in Cervidae. Rev. Sci. Tech. Off. Int. Epiz. 1992, 11(2): 551-567.

Wyatt JM, Pearson GR, Smerdon TN, Gruffydd_ Jones TJ, Wells GA, Wilesmith JW: Naturally occurring scrapie-like spongiform encephalopathy in five domestic cats. Vet. Rec. 1991, 129(11): 233-236.

Peer reviewed contribution to 11. International Conference on Production Diseases in Farm Animals, 12-16 August 2001, KVL, Frederiksberg, Denmark.

Reprints may be obtained from: M. G. Doherr, Department of Clinical Veterinary Medicine, University of Bern, Bremgartenstrasse 109a, CH - 3012 Bern, Switzerland. E-mail: marcus.doherr@itn.unibe.ch, tel: +41.31.631 2428, fax: 2538 . 